\title{
MECHANICAL ALLOYING - A NOVEL METHOD FOR SYNTHESIS AND PROCESSING OF MATERIALS
}

\author{
D. Oleszaik \\ Faculty of Materials Science and Engineering, Warsaw University of Technology \\ Narbutta 85, 02-524 Warsaw, Poland
}

High energy ball milling (mechanical alloying) has recently become a popular research topic. As the non-equilibrium processing method, this technique may be used for the synthesis of many materials, including metastable ones. In many cases these materials exhibit the structure and properties quite different from materials prepared by conventional methods. In this paper some examples of metastable structures synthesized by mechanical alloying are described. The results of mechanical alloying in the $\mathrm{Fe}-\mathrm{Al}$ system are presented as well.

PACS numbers: 61.43.-j, 61.43.Dq, 61.66.Dk

\section{Introduction}

Ball milling of powders is a very old technology but, until recently, it has only been used for pulverizing materials. It is now acknowledged that a number of interesting processes can occur during milling. For example, mechanical alloying (MA) can take place by mixing powders of different materials to produce entirely new alloys and compounds which do not normally form at room temperature or may be immiscible by conventional processing methods.

In addition, chemical reactions can be induced by the energy imparted to powders by mechanical means. In some cases, these reactions do not occur conventionally until very high temperatures are attained. In a properly controlled ball milling environment, a combination of mechano-chemistry induced by continual impact of powders and massive active surface area produced by pulverization stimulates many novel chemical reactions. Because of this, ball milling can be used to quickly and easily synthesize a variety of technologically useful materials which are very difficult to manufacture by other techniques. After milling, the powders are compressed and sintered to produce solid end products with bulk material properties.

\footnotetext{
*daol@inmat.pw.edu.pl
} 
There are many areas of technologically relevant scientific research which can be explored by ball milling, for example: the study of mechano-chemical reactions, including materials synthesis and reduction; gas-solid reactions; liquid-solid reactions; solid-solid reactions; amorphous materials production; novel materials. phases, compounds and alloys; mechanism of mechanical alloying; formation of nanostructures; novel composite materials.

In this paper selected examples of various materials synthesis by mechanical alloying/ball milling are discussed. Many other examples are left for future discussion (synthesis of high melting point ceramics like carbides, nitrides, borides or silicides, synthesis of high carbon steel, mechano-chemical reduction of metal oxides for producing pure metals, synthesis of permanent magnets and composite materials).

In the last part of this paper the detailed results of mechanical alloying in the $\mathrm{Fe}-\mathrm{Al}$ system are presented as well.

\section{Synthesis of equilibrium and non-equilibrium structures by mechanical alloying/ball milling}

\subsection{Intermetallics}

Intermetallics (intermetallic compounds) are important structural materials. Due to their ordered structure they exhibit good mechanical properties (strength, hardness, Young modulus), high melting point, and excellent corrosion resistance, coupled to a low density. However, these materials if produced by a conventional method, are brittle at room temperature. Therefore, the application of typical technologies to these materials, like cold working, is very limited. Manufacturing the intermetallics by MA followed by a consolidation of powders can help to overcome this problem.

The first attempt of producing intermetallics by MA was made by Ivanov [1] for the Al-Ni system. Nowadays MA is used for the synthesis of many intermetallics compounds, especially from the $\mathrm{Al}-\mathrm{Ti}, \mathrm{Al}-\mathrm{Ni}$, and $\mathrm{Al}-\mathrm{Nb}$ systems.

\subsection{Extended solid solutions}

Equilibrium solid solubility limits can be exceeded by nonequilibrium processing methods such as rapid solidification. This is also true for MA. There are a number of examples of this effect in the literature. Usually extended solid solubilities have been noted in the process of studying amorphization in various alloy systems. Schwarz et al. [2] found that the solubility limit of $\mathrm{Ti}$ in fcc $\mathrm{Ni}$ was approximately 28 at. $\%$ on MA of $\mathrm{Ti}$ and $\mathrm{Ni}$ powders. This may be compared with equilibrium solubility limit of only a few percent. In the $\mathrm{Ni}-\mathrm{Nb}$ system a considerably solid solubility enhancement by MA was observed by Lee et al. [3]. The terminal $\mathrm{Ni}$ fcc solid solution and the $\mathrm{Nb}$ bcc solid solution were found to be approximately 10 at.\% $\mathrm{Nb}$ and 10 at.\% $\mathrm{Ni}$, respectively. In equilibrium conditions these values are 4.2 at. $\% \mathrm{Nb}$ and 3.5 at.\% $\mathrm{Ni}$.

Extended solid solutions were also found in many Al-containing binary systems. Hellstern et al. [4] found an extended solid solubility of $\mathrm{Al}$ in bcc $\mathrm{Nb}$ of about 30 at.\% for $\mathrm{MA}$ of elemental $\mathrm{Nb}$ and $\mathrm{Al}$ powders, while in equilibrium the solubility of $\mathrm{Al}$ is smaller than 10 at.\%. Ivanov et al. [5] obtained an enhancement of 
solid solubility of $\mathrm{Al}$ in fcc $\mathrm{Ni}$ by MA of elemental $\mathrm{Ni}$ and $\mathrm{Al}$ powders from 4 at.\% at equilibrium up to 27 at.\% after MA. In all described systems $(\mathrm{Ni}-\mathrm{Ti}, \mathrm{Ni}-\mathrm{Nb}$, $\mathrm{Nb}-\mathrm{Al}, \mathrm{Ni}-\mathrm{Al}$ ), metastable equilibrium between the bcc (or fcc) solid solution and an amorphous phase is apparently responsible for the extended solid solubility.

Extended solid solubility (formation of solid solutions) was also observed in many binary systems immiscible in solid state or even in liquid state. Due to MA it is possible to manufacture alloys from the $\mathrm{Fe}-\mathrm{Cu}, \mathrm{Fe}-\mathrm{Ag}, \mathrm{Cu}-\mathrm{Ag}, \mathrm{Cu}-\mathrm{W}$, and $\mathrm{Cu}-\mathrm{Pb}$ systems, used for electric contacts and bearings. For example, the $\mathrm{Fe}-\mathrm{Cu}$ system exhibits immiscibility in a liquid state. Simultaneously, in a solid state the mutual solubility of both components is very limited, smaller than 0.1 at.\%. However, the MA process of $\mathrm{Fe}-70$ at.\% Cu powder mixture resulted in the formation of supersaturated fcc solid solution.

The formation of supersaturated solid solutions was also observed in binary $\mathrm{Mg}$-containing alloys, which are usually immiscible. For example, the solubility of $\mathrm{Mg}$ in $\mathrm{Ti}$ has been enhanced from 0.2 at.\% in equilibrium up to 6 at.\% after MA [6]. $\mathrm{Mg}$-based alloys containing $\mathrm{Fe}(\mathrm{Ni}, \mathrm{Co}, \mathrm{Cu}$ or $\mathrm{Ti}$ ) are used in marine industry as primary batteries, due to their hydrogen absorption/desorption ability.

\subsection{Disordering by mechanical milling}

It is well known that large strains in plastic deformation (> 20\%) can destroy long-range chemical order in ordered alloys [7]. Studies of such disordering are therefore usually limited to ordered alloys and intermediate phases which exhibit extensive ductility such as $\mathrm{Cu}_{3} \mathrm{Au}$ and $\mathrm{Ni}_{3} \mathrm{Mn}$. High energy ball milling extends the possibility for studying deformation-induced disorder to nominally brittle ordered alloys and intermetallic compounds.

Hellstern et al. [8] studied the changes in structural and thermodynamic properties of the AlRu intermatallic with milling time. Milling of ordered bcc AlRu compound induced a decrease in a long-range ordering (LRO) parameter $S$ from 1.0 to 0.7. AlRu did not exhibit amorphization but showed the development of a fine nanocrystalline grain size. The crystal size at long milling times saturated at about $7 \mathrm{~nm}$ and the lattice strain at $3 \%$. It was concluded that most of the disordering was a consequence of the crystal refinement as opposed to the density of antiphase boundaries.

Seki et al. [9] reported the structural changes in ball milled CuTi intermetallic compound. The LRO parameter $S$ decreased with milling time and saturated at about 0.5 . Amorphization did not occur for this compound.

Contrary, Jang et al. [10] observed a complete disordering by ball milling of the ordered $\mathrm{Ni}_{3} \mathrm{Al}$ intermetallic compound which has an $\mathrm{Ll}_{2}$ (ordered fcc) crystal structure. The value of LRO parameter $S$ decreases monotonically from 1 to 0 after several hours of processing.

Oehring et al. [11] has measured a decrease in the LRO parameter $S$ on ball milling of the $\mathrm{A} 15$ compound $\mathrm{Nb}_{3} \mathrm{Al}$. Although $S$ only decreases from 1.0 to 0.8 before the A15 structure transforms to a bec solid solution, he attributes the transformation to the increase in the free energy of the A15 structure by disordering. The resulting disordering energy estimated for this change in $S$ amounts to 
$2 \mathrm{~kJ} / \mathrm{mol}$, which is a larger value than the stored energy from the $43 \mathrm{~nm}$ diameter grain boundaries $(0.7 \mathrm{~kJ} / \mathrm{mol})$ or elastic strain energy $(0.09 \mathrm{~kJ} / \mathrm{mol})$.

\subsection{Amorphization by mechanical alloying/milling}

The research using MA during the last decade has been dominated by the use of this technique for solid state amorphization. One can divide amorphization by ball milling into two categories: (1) mechanical alloying (MA) of elemental . powders involving material transfer between the components and (2) mechanical milling (MM) of a single composition (for example an intermetallic compound).

Amorphous metallic phases have been produced for many years by rapid solidification technique. Amorphization from the solid state gained attention in 1983 with the discoveries of amorphization by hydrogenation of $\mathrm{Zr}_{3} \mathrm{Rh}$ by Yeh et al. [12], amorphization by diffusion between thin film sandwiches of crystalline La and Au by Schwarz and Jolnnson [13], and amorphization by mechanical alloying of crystalline $\mathrm{Ni}$ and $\mathrm{Nb}$ powders by Koch et al. [14].

The first examples of amorphization of intermetallic compounds by mechanical milling were presented by Ermakov et al. [15] in the Y-Co and Gd-Co systems.

The fundamentals of thermodynamics and kinetic factors of amorphization in metallic systems are reviewed by Jolnnson [16] and Weeber et al. [17].

MA has been successfully applied for the amorphization of powder mixtures in many systems, like Ti-M and $\mathrm{Zr}-\mathrm{M}(\mathrm{M}=\mathrm{Fe}, \mathrm{Ni}, \mathrm{Co}, \mathrm{Cu}, \mathrm{Mn})$, binary $\mathrm{Al}$ alloys, $\mathrm{Nb}-\mathrm{Ti}, \mathrm{Ni}, \mathrm{Fe}$. Usually the composition ranges of amorphization by MA are wider than by rapid solidification method and correspond to the existence of equilibrium intermetallic compounds at the phase diagrams.

\subsection{Crystallization of amorphous alloys by mechanical milling}

While many crystalline materials have been amorphized, there are relatively few reports of the crystallization of amorphous alloys by ball milling (so-called mechanical crystallization).

The crystallization of amorphous Ni-Zr alloys was reported by Eckert et al. [18], Mizutani et al. [19] and Petzold et al. [20]. The transformation was observed after prolonged milling time or after an increase in milling intensity. It was assumed that the increased kinetic energy of the milling media raised the temperature of the powders such that in situ crystallization could occur. The powder surfaces may be hotter than the measured macroscopic temperature of the ball mill, which is usually several hundreds degree below the crystallization temperature for the respective alloy.

If the crystallization was observed after prolonged milling times, it was attributed to contamination by the milling media and/or atmosphere. It was believed that oxygen contamination was responsible for the crystallization of $\mathrm{Ni}-\mathrm{Zr}$ alloys, while accumulation of $\mathrm{Fe}$ and $\mathrm{Cr}$ impurities from milling media (mill, balls) beyond a critical concentration pushes the alloy composition out of the amorphous range and leads to a crystallization process.

In the case of milling an amorphous structure, the thermodynamics favours more stable crystalline phases and the equilibrium crystalline structure. The transformation from the amorphous to crystalline phase by ball milling means that the 
kinetics of the transformation must be influenced by ball milling. Introduction of impurities (chemistry change) and local temperature increases are possibilities for enhancement of the crystallization kinetics. However, the amorphous $\rightarrow$ crystalline transformations still remain not well understood. Perhaps milling introduces defects, e.g. increased free volume in the amorphous alloys, which could accelerate diffusion and therefore crystallization.

\subsection{Nanocrystalline materials by mechanical alloying/milling}

Nanometer-sized crystalline materials (nanocrystalline materials) were discovered by Gleiter et al. [21]. These materials are polycrystals with very small crystallite sizes $(<100 \mathrm{~nm})$. Therefore, they contain a very large grain boundary area and are apparently composed of randomly oriented high angle boundaries.

The first nanocrystalline materials were produced by evaporation technique [22] in a high purity noble gas atmosphere followed by condensation and then compaction in an ultra-high vacuum.

It has been shown recently that nanocrystalline materials can also be synthesized by high energy ball milling of elemental powders, intermetallic compound powders or powders of immiscible alloy systems [23-25]. The stability and properties of such structures have not been studied systematically, however, ball milling should be a practical method of producing large quantities of nanocrystalline materials.

\subsection{Quasicrystalline materials by mechanical alloying}

In 1984 Shechtman et al. [26] discovered an $\mathrm{Al}-\mathrm{Mn}$ phase that exhibited a sharp electron diffraction pattern with icosahedral point symmetry. This discovery attracted considerable interest in such "quasicrystals". Although a few stable quasicrystals have been found, most of the known quasicrystals are thermodynamically metastable. They are usually produced by nonequilibrium methods such as rapid solidification, ion beam mixing, transformation of an amorphous phase or mechanical alloying.

Ivanov et al. [27] and Eckert et al. [28] synthesized icosahedral phases by MA in $\mathrm{Mg}-\mathrm{Zn}-\mathrm{Al}$ and $\mathrm{Al}-\mathrm{Cu}-\mathrm{Mn}$ alloys, respectively. They believe the formation of the icosahedral phase during MA is due to an interdiffusion reaction between the components. The advantage of synthesizing quasicrystalline materials by MA is the possibility of producing large quantities of powder which might be compacted to obtain bulk material for physical properties studies or potential technical applications.

\section{Mechanical alloying in the Fe-Al system}

\subsection{Introduction}

As it was shown earlier, mechanical alloying has proved to be a useful technique to prepare nanocrystalline alloys and compounds. Numerous works on MA are focused on the development of nanostructured Al-based intermetallic compounds due to their good mechanical properties and corrosion resistance at relatively high temperatures coupled to a low density [29]. High strength alloys based 
on nanocrystalline intermetallic compounds from the $\mathrm{Fe}-\mathrm{Al}$ system are also studied, namely $\mathrm{Fe}_{3} \mathrm{Al}$ and $\mathrm{FeAl}[30]$.

During the last years MA has been also successfully applied for synthesis of amorphous materials by ball milling of the mixtures of elemental crystalline powders or powders of intermetallic compounds. The formation of an amorphous structure in the $\mathrm{Fe}-\mathrm{Al}$ system has been also confirmed in the composition range corresponding to the equilibrium $\mathrm{FeAl}_{2}, \mathrm{Fe}_{2} \mathrm{Al}_{5}$ and $\mathrm{FeAl}_{3}$ intermetallic compounds [31].

The aim of this work was to study systematically the MA processes in the $\mathrm{Fe}-\mathrm{Al}$ system in a wide range of compositions. Special attention was paid to the possibilities of the synthesis of nanocrystalline Fe-based intermetallic compounds and to monitoring the crystalline-to-amorphous transformations through different stages of the synthesis process.

\subsection{Experimental}

Powders of crystalline $\mathrm{Fe}$ and $\mathrm{Al}$ with a purity of $99.9 \%$ and particle sizes of 100 and $40 \mu \mathrm{m}$, respectively, were used for the experiments. The powders were mixed in the following starting compositions: $\mathrm{Fe}-10,20,30,50,60,66.6,72$, 75 , and 85 at.\% Al. The mechanical alloying processes were performed in a conventional horizontal low energy ball mill rotated at a speed of 120 revmin $^{-1}$. Cylindrical stainless steel vials of inner diameter $130 \mathrm{~mm}$ and height $128 \mathrm{~mm}$ and stainless steel balls of diameter $9.4 \mathrm{~mm}$ were used. The ball-to-powder weight ratio was 50:1. The vials were loaded and sealed under an argon atmosphere and all powder handling was performed in a glove box.

During the studies two experimental techniques were applied for the structure characterization. X-ray diffraction investigations (XRD) were performed on a Philips PW 1830 diffractometer in a continuous scanning mode using $\mathrm{Cu} K_{\alpha}$ or Co $K_{\alpha}$ radiation $(\lambda=0.154$ or $0.179 \mathrm{~nm})$. Small quantities of the powder were withdrawn at different time intervals to evaluate the extent of alloying. X-ray studies allowed us to calculate the parameters describing the obtained structures (crystallite size, lattice strain, lattice parameter).

Differential scanning calorimetry (DSC) measurements were carried out in a Perkin Elmer DSC 7 unit within the temperature range $320-1000 \mathrm{~K}$ at a continuous heating rate of $20 \mathrm{~K} \mathrm{~min}^{-1}$. This technique allowed the number and temperature ranges of registered heat effects determination. The enthalpies of the observed transformations were calculated as well.

\subsection{Results and discussion}

Figure 1 shows the XRD patterns of the $\mathrm{Fe}-50$ at.\% Al powder mixture subjected to milling for increasing time. The diffraction lines corresponding to fcc $\mathrm{Al}$ become weak and disappear after $400 \mathrm{~h}$ of processing. For the samples with a smaller Al content $(10,20$, and 30 at.\%) these peaks disappear after a shorter milling time, e.g. for the $\mathrm{Fe}-20$ at.\% Al powders after only $50 \mathrm{~h}$ of alloying. Simultaneously, the bcc Fe diffraction lines become broad and shift to the low angle side of the spectrum with increasing milling time. This shift of the diffraction lines can be attributed to the increase in the lattice parameter of the $\mathrm{bcc} F \mathrm{Fe}$ due to the dissolving of aluminium atoms. Since the superlattice lines are 


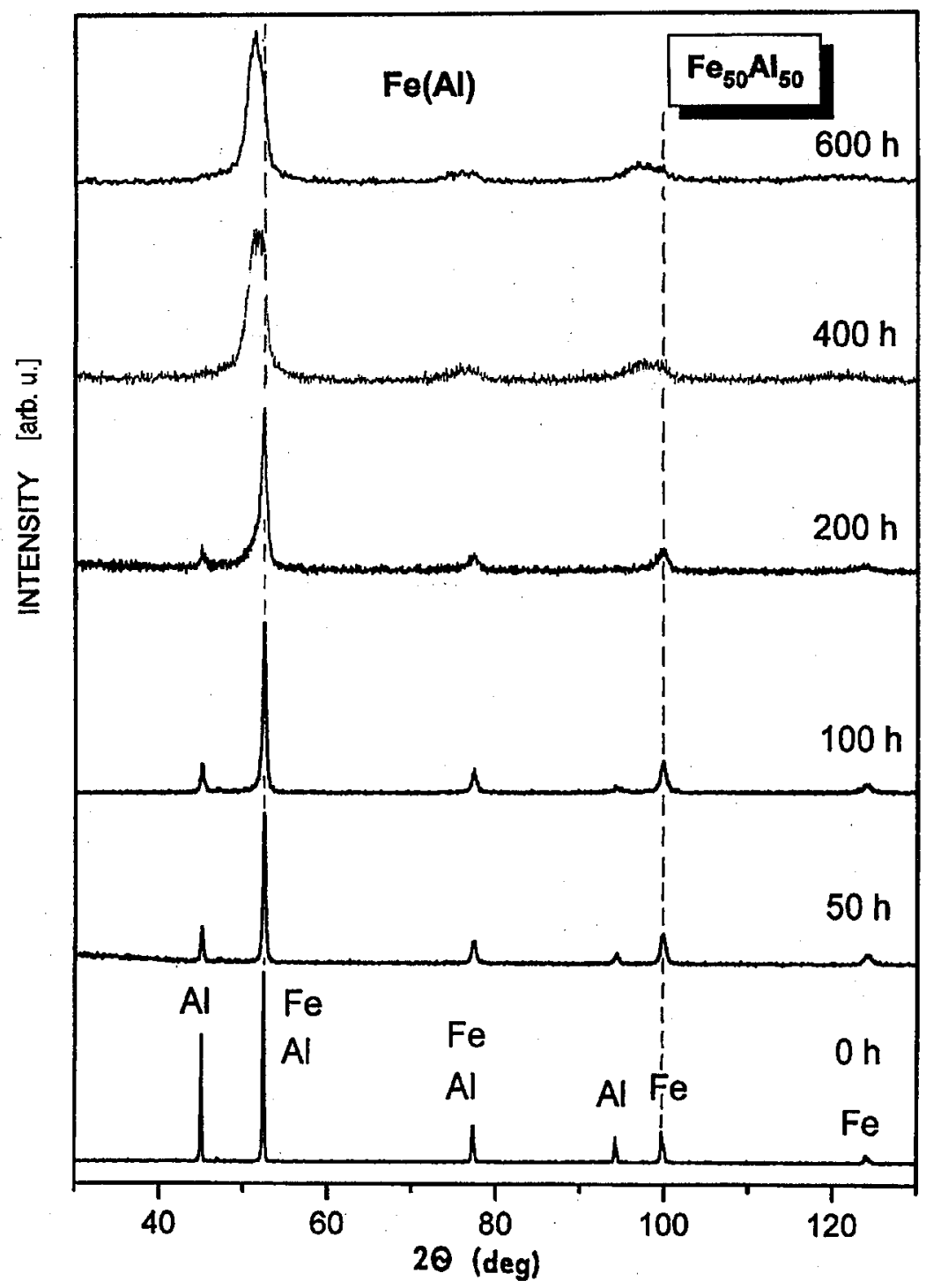

Fig. 1. The XRD patterns of Fe -50 at. $\%$ Al powder mixture subjected to MA for increasing time.

not observed, it can be deduced that a disordered bcc solid solution of aluminium in iron is formed. The value of lattice parameter $a$ of this $\mathrm{Fe}(\mathrm{Al})$ solid solution after $600 \mathrm{~h}$ of MA, calculated from the shift of $\mathrm{Fe}$ (211) high angle diffraction line, reaches $0.2935 \mathrm{~nm}$, compared with $0.2867 \mathrm{~nm}$ for pure $\mathrm{Fe}$. The results for selected compositions are shown in Fig. 2.

The observed broadening of the diffraction lines after MA can be attributed to the refinement of crystal size and increase in internal strains. To separate the 


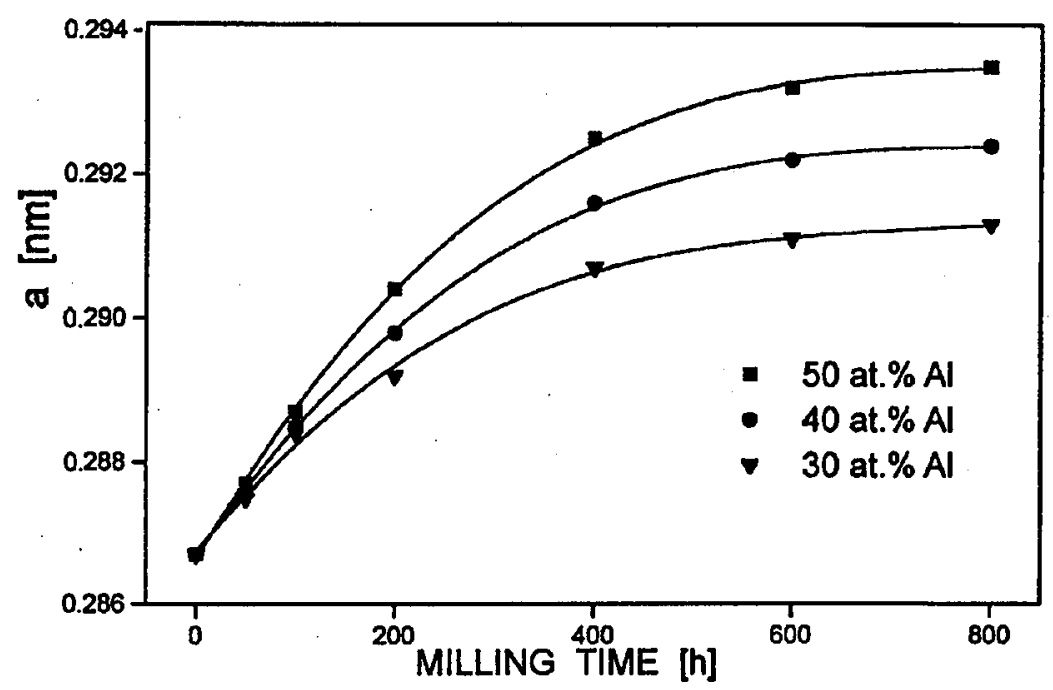

Fig. 2. Changes of lattice parameters $a$ of $\mathrm{Fe}(\mathrm{Al})$ solid solutions versus milling time.

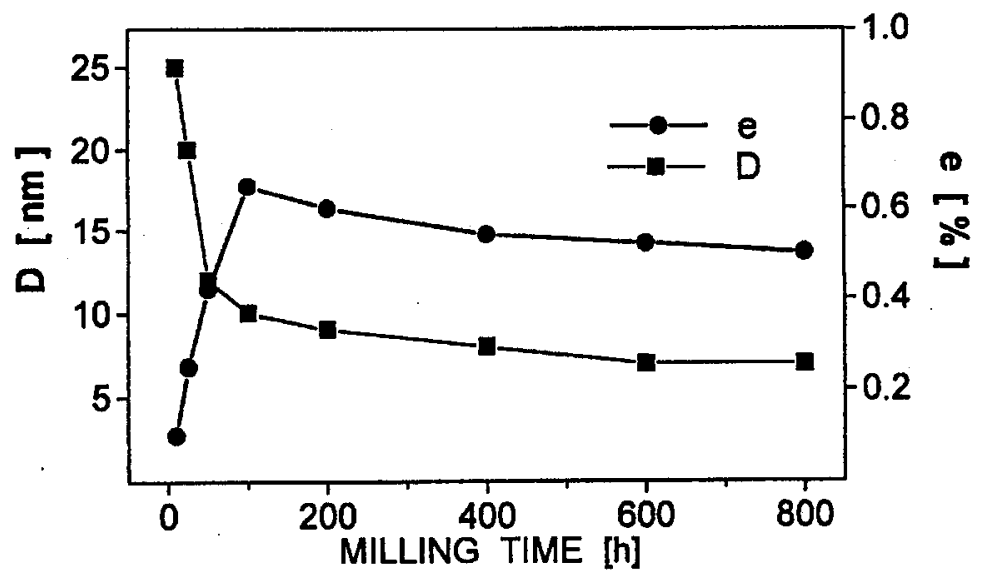

Fig. 3. The dependence of mean crystallite size $D$ and lattice strain $e$ on MA time.

effect of crystallite size reduction from that of lattice distortion, the approach of Williamson and Hall has been adopted [32]. By plotting the measured broadening as a function of scattering vector, one can obtain from the ordinate intercept the mean crystallites size $D$ and from the slope - the r.m.s. (root mean square) strain $e$ [33]. The dependence of calculated mean crystallites size and strain in the $\mathrm{Fe}(\mathrm{Al})$ on milling time is plotted in Fig. 3. For all the alloys containing up to 50 at.\% Al the bcc solid solution, characterized by crystallites size of several nanometers, was synthesized. Besides, an enhancement of the lattice strain is observed. It increases at the first stage of powders deformation, reaches a maximum and then decreases 
upon further milling. The maximum at a certain strain level can be explained by the change in the deformation mechanism from plastic deformation via generation and movemient of dislocations to grain boundary gliding. Both the maximum level of strain observed $(0.95 \%$ for $\mathrm{Fe}-30$ at. $\% \mathrm{Al})$ and its dependence on milling time are typical for ball milled alloys [34].

The DSC curves registered for the $\mathrm{Fe}-50$ at.\% $\mathrm{Al}$ samples after increasing milling time are collected in Fig. 4. At early processing times large exothermic effects are visible. These effects gradually vanish with longer processing time and completely disappear after $400 \mathrm{~h}$ of MA. This milling time corresponds to the decay of Al lines at the XRD pattern. As X-ray studies of the samples after short MA time (25-100 h) and subsequent heating in the DSC showed, the equilibrium $\mathrm{FeAl}_{2}$ compound is formed. This process is accompanied by a distinct exothermal effect at the DSC curves.

On the other hand, heating the samples in the DSC after long MA time leads to the formation of the $\mathrm{FeAl}$ intermetallic compound, i.e. a disordered bcc $\mathrm{Fe}(\mathrm{Al})$

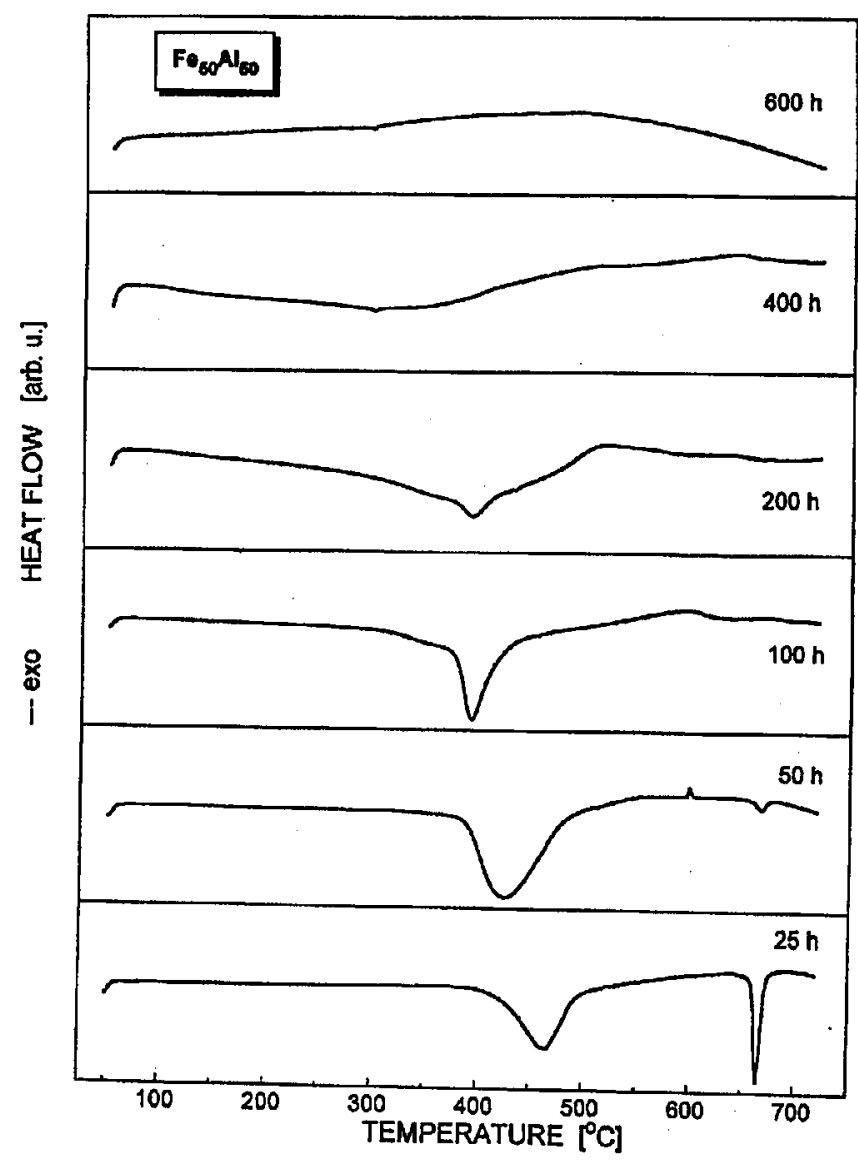

Fig. 4. DSC curves registered for $\mathrm{Fe}-50$ at.\% Al samples after increasing MA time. 
solid solution transforms into an ordered $\mathrm{FeAl}$ phase, as $\mathrm{X}$-ray studies show. This process is practically not accompanied by any calorimetric effects.

The calculated value of lattice parameter $a$ of the $\mathrm{FeAl}$ compound equals $0.2900 \mathrm{~nm}$ and is close to the equilibrium value of $0.2895 \mathrm{~nm}$. The obtained $\mathrm{FeAl}$ compound is a nanocrystalline one, with a mean crystallite size about $10 \mathrm{~nm}$.

A completely different sequence of phase transformations upon mechanical alloying was observed for Al-rich starting powder mixtures (60-85 at.\% Al). Figure 5 shows a sequence of XRD patterns obtained for $\mathrm{Fe}-75$ at.\% $\mathrm{Al}$ samples with increasing milling time. The originally sharp diffraction lines of $\mathrm{Fe}$ and $\mathrm{Al}$ gradually become broader and their intensity decreases with increasing milling time. Assuming that the observed broadening is due to the reduction of crystallite size and applying the Scherrer formula for average crystallite size calculations before amorphization, the value of about $10 \mathrm{~nm}$ has been obtained. This size of crystallites seems to be favourable to the formation of the amorphous phase, which develops at the $\mathrm{Fe} / \mathrm{Al}$ interfaces. Further milling leads to an amorphous structure formation in the whole sample volume and a diffraction halo typical for amorphous material

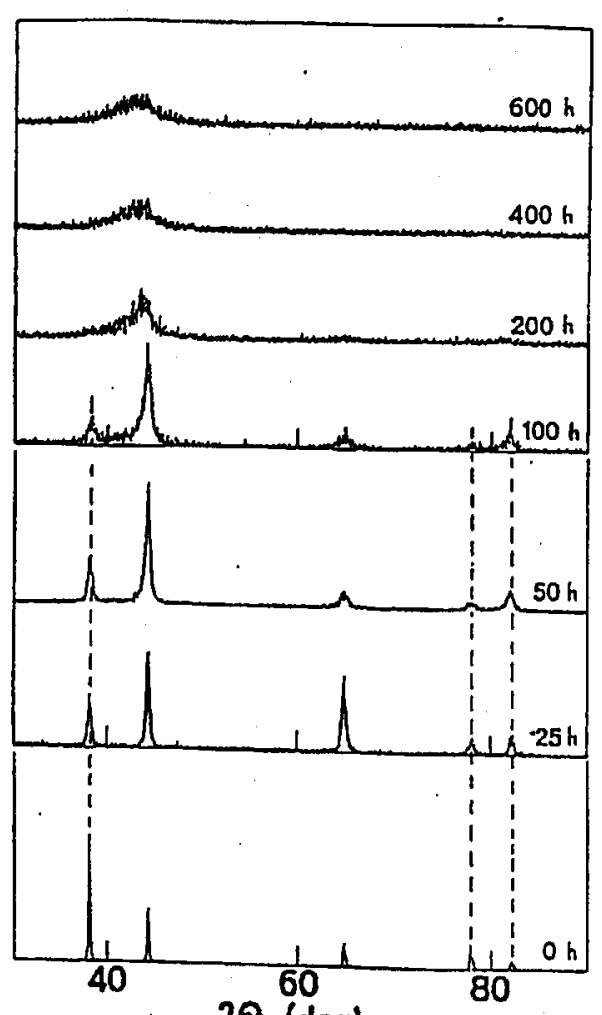

Fig. 5
20 (deg)

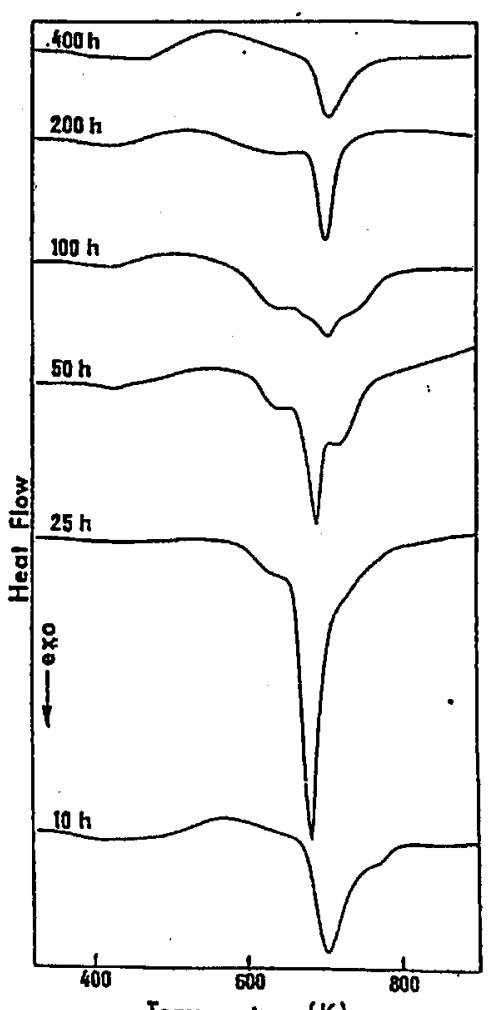

Fig. 6

Fig. 5. XRD spectra of $\mathrm{Fe}-75$ at.\% $\mathrm{Al}$ powder mixtures after various milling times.

Fig. 6. DSC curves of $\mathrm{Fe}-75$ at. $\% \mathrm{Al}$ alloy recorded at various stages of synthesis. 
is registered. It is worthwhile to add that, before amorphization, the shift of the $\mathrm{Fe}$ and $\mathrm{Al}$ diffraction lines is not observed. This result suggests that the amorphous phase forms directly from the starting mixture of the elements, without the formation of other phases.

The DSC curves registered for $\mathrm{Fe}-75$ at.\% Al alloy after different milling times are presented in Fig. 6. Many overlapping exothermic effects are visible at the calorimetric curves and their number, temperature range, and heat released depend on milling time. However, the total heat evolved reaches the maximum values for relatively short milling time $(25-50 \mathrm{~h})$. Simultaneously, after prolonged milling the DSC curves stabilize, exhibiting one exothermic effect. Taking into account the XRD results one can assume that this effect is attributed to the crystallization process of the amorphous phase formed by MA. As the XRD studies of the samples after heating in the DSC showed, $\mathrm{Fe}_{2} \mathrm{Al}_{5}$ intermetallic compound was detected as a crystallization product. Existence of $\mathrm{Fe}_{2} \mathrm{Al}_{5}$ compound instead of $\mathrm{FeAl}_{3}$ one, corresponding to the starting powder mixture, can be explained by a small shift in the alloy composition, as the chemical analysis showed.

\subsection{Conclusions}

The MA processes performed for $\mathrm{Fe}-\mathrm{Al}$ powder mixtures containing up to 50 at.\% $\mathrm{Al}$ resulted in the formation of supersaturated bcc $\mathrm{Fe}(\mathrm{Al})$ nanocrystalline solid solutions. These solid solutions were characterized by a minimum crystallite size and maximum strain level of $5 \mathrm{~nm}$ and $0.65 \%$, respectively. For $\mathrm{Fe}-50$ at.\% $\mathrm{Al}$ alloy the lattice parameter of the $\mathrm{Fe}(\mathrm{Al})$ reached $0.2935 \mathrm{~nm}$, compared with 0.2867 for pure Fe.

The MA processes performed for Al-rich powder mixtures resulted in the formation of an amorphous phase. The amorphous phase was obtained for the alloy compositions corresponding to equilibrium $\mathrm{FeAl}_{2}, \mathrm{Fe}_{2} \mathrm{Al}_{5}$, and $\mathrm{FeAl}_{3}$ intermetallic compounds, whose formation by solid state reaction was kinetically suppressed. Heating of the samples in the DSC resulted in the crystallization of the synthesized amorphous alloys. The crystallization temperatures depended on the alloy composition and were in the range $600-800 \mathrm{~K}$. One-stage crystallization was observed and equilibrium intermetallic phases appeared as the crystallization products.

\section{References}

[1] E. Ivanov, T. Grigorieva, G. Golubkova, V. Boldyriev, A.B. Fasman, Mater. Lett. 1, 51 (1988).

[2] R.B. Schwarz, R.R. Petrich, C.K. Saw, J. Non-Cryst. Solids 76, 281 (1985).

[3] P.Y. Lee, C.C. Koch, J. Non-Cryst. Solids 94, 88 (1987).

[4] E. Hellstern, L. Schultz, R. Bormann, D. Lee, Appl. Phys. Lett. 53, 1399 (1988).

[5] E. Ivanov, T. Grigorieva, G. Golubkova, V. Boldyriev, A.B. Fasman, S.D. Mikhailenko, O.T. Kalinina, Mater. Lett. 7, 51 (1988).

[6] R. Sundaresan, F.H. Froes, in: New Materials by Mechanical Alloying Technique, Eds. E. Artz, L. Schultz, Oberursel (Germany) 1989, p. 253.

[7] N.S. Stoloff, Prog. Mater. Sci. 13, 77 (1966).

[8] E. Hellstern, H.J. Fecht, Z. Fu, W.L. Johnson, J. Appl. Phys. 65, 305 (1989). 
[9] Y. Seki, W.L. Johnson, in: Solid State Processing, Eds. A.H. Clauer, J.J. de Barbadillo, TMS, Warrendale (PA) 1990, p. 287.

[10] J.S.C. Jang, C.C. Koch, J. Mater. Res. 5, 498 (1990).

[11] M. Oehring, R. Bormann, J. Phys. Colloq. C4-51, 169 (1990).

[12] X.L. Yeh, K. Samwer, W.L. Johnson, Appl. Phys. Lett. 42, 242 (1983).

[13] R.B. Schwarz, W.L. Johnson, Phys. Rev. Lett. 51, 415 (1983).

[14] C.C. Koch, O.B. Cavin, C.G. McKamey, J.O. Scarbrough, Appl. Phys. Lett. 43, 1017 (1983).

[15] A.E. Yermakov, E.E. Yurchikov, V.A. Barinov, Phys. Met. Metallogr. 52, 50 (1981).

[16] W.L. Johnson, Prog. Mater. Sci. 30, 81 (1986).

[17] A.W. Weeber, H. Bakker, Z. Chem. Phys. 157, 221 (1988).

[18] J. Eckert, L. Schultz, E. Hellstern, J. Appl. Phys. 64, 3224 (1988).

[19] U. Mizutani, C.H. Lee, J. Mater. Sci. 25, 399 (1990).

[20] F. Petzold, B. Scholz, H. Kunze, Ref. [6], p. 111.

[21] H. Gleiter, P. Marquardt, Z. Metall. 75, 263 (1984).

[22] R. Birringer, H. Gleiter, H.P. Klein, P. Marquardt, Phys. Lett. A 102, 365 (1984).

[23] H.J. Fecht, E. Hellstern, Z. Fu, W.L. Johnson, Metall. Trans. A 21, 2333 (1990).

[24] E. Hellstern, H.J. Fecht, C. Garland, W.L. Johnson, Mater. Res. Soc. Symp. Proc. 132, 139 (1989).

[25] J.S.C. Jang, C.C. Koch, J. Mater. Res. 5, 325 (1990).

[26] D. Shechtman, I. Blech, D. Gratias, J.W. Cahn, Phys. Rev. Lett. 53, 1951 (1984).

[27] E. Ivanov, I.G. Konstanchuk, B.D. Bokhonov, V.V. Boldyriev, React. Solids 7, 167 (1989).

[28] J. Eckert, L. Schultz, K. Urban, Appl. Phys. Lett. 55, 117 (1989).

[29] R.A. Varin, M.B. Winnicka, Mater. Sci. Eng. A 137, 93 (1991).

[30] E. Bonetti, G. Scipione, S. Enzo, R. Frattini, L. Schiffini, Nanostruct. Mater. 6, 397 (1995).

[31] B. Huang, N. Tokizane, K.N. Ishihara, P.H. Shingu, J. Non-Cryst. Solids 117/118, 688 (1990).

[32] G.K. Williamson, W.H. Hall, Acta Metall. 1, 22 (1953).

[33] H.P. Klug, L. Alexander, X-ray Diffraction Procedures for Polycrystalline and Amorphous Materials, Wiley, New York 1974, p. 661.

[34] H.J. Fecht, E. Hellstern, Z. Fu, W.L. Johnson, Adv. Powder Metall. 1, 111 (1989). 